\title{
Uric Acid-Induced Enhancements of Kv1.5 Protein Expression and Channel Activity via the Akt-HSF1-Hsp70 Pathway in HL-1 Atrial Myocytes
}

\author{
Fikri Taufiq, MD; Nani Maharani, MD, PhD; Peili Li, MD, PhD; \\ Yasutaka Kurata, MD, PhD; Nobuhito Ikeda, PhD; Masanari Kuwabara, MD, PhD; \\ Naoyuki Otani, MD, PhD; Junichiro Miake, MD, PhD; Akira Hasegawa, PhD; \\ Motokazu Tsuneto, PhD; Yasuaki Shirayoshi, PhD; Haruaki Ninomiya, MD, PhD; \\ Tatsuya Saitoh, PhD; Akira Nakai, MD, PhD; \\ Kazuhiro Yamamoto, MD, $\mathrm{PhD}$; Ichiro Hisatome, $\mathrm{MD}, \mathrm{PhD}$
}

\begin{abstract}
Background: Intracellular uric acid is known to increase the protein level and channel current of atrial Kv1.5; however, mechanisms of the uric acid-induced enhancement of Kv1.5 expression remain unclear.

Methods and Results: The effects of uric acid on mRNA and protein levels of Kv1.5, as well as those of Akt, HSF1 and Hsp70, in $\mathrm{HL}-1$ cardiomyocytes were studied by using qRT-PCR and Western blotting. The uptake of uric acid was measured using radio-labeled uric acid. The Kv1.5-mediated channel current was also measured by using patch clamp techniques. Uric acid up-taken by HL-1 cells significantly increased the level of Kv1.5 proteins in a concentration-dependent manner, with this increase abolished by an uric acid transporter inhibitor. Uric acid slowed degradation of Kv1.5 proteins without altering its mRNA level. Uric acid enhanced phosphorylation of Akt and HSF1, and thereby increased both transcription and translation of Hsp70; these effects were abolished by a PI3K inhibitor. Hsp70 knockdown abolished the uric acid-induced increases of Kv1.5 proteins and channel currents.
\end{abstract}

Conclusions: Intracellular uric acid could stabilize Kv1.5 proteins through phosphorylation of Akt and HSF1 leading to enhanced expression of $\mathrm{Hsp} 70$.

Key Words: Akt; Heat shock factor 1; Heat shock protein 70; Kv1.5; Uric acid

$\mathbf{U}$ ric acid is the end product of purine catabolism in a human body. ${ }^{1}$ Many reports indicated a positive correlation between serum uric acid concentration and morbidity or mortality of cardiovascular diseases including atrial fibrillation (AF). ${ }^{2-5}$ It is well known that increases in potassium channel currents shorten the atrial refractory period to facilitate the development of re-entry circuits, leading to AF. Escalation of cardiovascular morbidity and mortality has been attributed to oxidative stress. ${ }^{6,7}$ Our previous study indicated that uric acid could

\section{Editorial p 705}

increase the protein level of voltage-gated potassium channel subfamily 1 number 5 (Kv1.5) by increasing the NADPHdependent oxidative stress level in HL-1 mouse atrial myocytes. ${ }^{8}$ Uric acid may lead to inductions of arrhythmias including AF and resultant increases in cardiovascular mortality via the enhancement of Kv1.5 expression. However, precise molecular mechanisms underlying the uric

Received October 2, 2018; revised manuscript received November 30, 2018; accepted December 18, 2018; J-STAGE Advance Publication released online February 20, 2019 Time for primary review: 29 days

Division of Regenerative Medicine and Therapeutics, Department of Genetic Medicine and Regenerative Therapeutics, Tottori University Graduate School of Medical Science, Yonago (F.T., P.L., N.I., A.H., M.T., Y.S., I.H.), Japan; Department of Pharmacology and Therapeutics, Faculty of Medicine Diponegoro University, Semarang (N.M.), Indonesia; Department of Physiology II, Kanazawa Medical University Faculty of Medicine, Ishikawa (Y.K.); Department of Cardiology, Toranomon Hospital, Tokyo (M.K.); Department of Clinical Pharmacology and Therapeutics, Oita University Faculty of Medicine, Oita (N.O.); Division of Cardiovascular Medicine, Department of Molecular Medicine and Therapeutics, Tottori University Faculty of Medicine, Yonago (J.M., K.Y.); Department of Biological Regulation, Tottori University, Yonago (H.N.); Division of Inflammation Biology, Institute for Enzyme Research, Tokushima University, Tokushima (T.S.); Laboratory of Bioresponse Regulation, Graduate School of Pharmaceutical Sciences, Osaka University, Suita (T.S.); and Department of Biochemistry and Molecular Biology, Yamaguchi University School of Medicine, Ube (A.N.), Japan

Mailing address: Yasutaka Kurata, MD, PhD, Department of Physiology II, Kanazawa Medical University, 1-1 Daigaku, Uchinada-machi, Kahoku-gun, Ishikawa 920-0293, Japan. E-mail: yasu@kanazawa-med.ac.jp

ISSN-1346-9843 All rights are reserved to the Japanese Circulation Society. For permissions, please e-mail: cj@j-circ.or.jp 
acid-induced increase in the protein expression of Kv1.5 remains unclear.

The intracellular uric acid level is regulated by uric acid transporters (UATs). ${ }^{9}$ The intracellular accumulation of uric acid via activation of influx UATs could cause cellular damages through several signaling pathways. ${ }^{6}$ It has been suggested that reactive oxygen species (ROS) could activate the phosphoinositide-3-kinase (PI3K)/Akt/mammalian target of rapamycin (mTOR) pathway through reversible inactivation of phosphatase and tensin homolog deleted from chromosome 10 (PTEN). ${ }^{10,11}$ Although uric acid could stimulate ROS production, it remains unknown whether uric acid enhances the protein expression of Kv1.5 via the ROS-dependent PI3K/Akt/mTOR pathway.

Under stress conditions, heat shock protein 70 (Hsp70) prevents protein misfolding and aggregation. Expression of Hsp70 is regulated by a transcription factor, heat shock factor 1 (HSF1). The protein quality control machinery involving Hsp70 plays pivotal roles in appropriate protein folding, disposal of miss-folded proteins and regulation of protein degradation. Accordingly, activation of HSF1 by phosphorylation and subsequent trimerization and a resultant increase of $\mathrm{Hsp} 70$ are critical events by which cells overcome stress and have less damage. ${ }^{12,13}$ Both HSF1 and Hsp70 have been reported to regulate the expression of Kv1.5. We have reported that HSF1 activates SAP97, an anchoring protein of Kv1.5.14 Overexpression of Hsp70 also prolonged the half-life of Kv1.5 proteins and enhanced Kv1.5 channel currents via increasing its channel density on the cell membrane. ${ }^{15}$

In the present study, we investigated intracellular mechanisms for the uric acid-induced enhancement of the expression of Kv1.5, and demonstrated that intracellularly accumulated uric acid facilitated phosphorylation of Akt and HSF1 to increase Hsp70, which stabilizes Kv1.5 proteins.

\section{Methods}

\section{Cell Culture}

HL-1 cells were cultured in Claycomb medium supplemented with $10 \%$ fetal bovine serum, $1 \%$ norepinephrine, $1 \%$ penicillin-streptomycin, and $1 \%$ L-glutamin on culture dishes coated with $0.02 \%$ gelatin-fibronectin in an incubator at $37^{\circ} \mathrm{C}$ with $5 \% \mathrm{CO}_{2}$.

\section{Reagents}

Uric acid (Sigma, Missouri, USA) was dissolved in boiled culture medium, and filtered using a $0.22-\mu \mathrm{m}$ filter at room temperature. It was applied to cells at $60-70 \%$ confluence at the final concentrations of 4-7 mg/dL. The guideline for the management of hyperuricemia and gout in Japan ${ }^{\mathbf{1 6}}$ has indicated that hyperuricemia is defined as the serum urate level $>7 \mathrm{mg} / \mathrm{dL}$; thus, we define hyperuricemic conditions as uric acid concentrations of $\geq 7 \mathrm{mg} / \mathrm{dL}$, as reported previously. ${ }^{8}$ Benzbromarone (Wako, Osaka, Japan), an inhibitor of the voltage-driven uric acid influx transporter, URATv1, was used at a concentration of $10 \mu \mathrm{mol} / \mathrm{L}$.

\section{Knockdown of Hsp70 by a Small Interfering RNA (siRNA)}

An oligonucleotide siRNA against Hsp70 was used to knockdown Hsp70. A scramble siRNA was used as a control. Cells were transfected with siRNA using lipofectamine 3000 (Thermo Fisher Scientific, Tokyo, Japan) according to the manufacturer's instructions. The sequences of siRNA were as follows:
Hsp70 siRNA sense,

5'-CUGGAGAUCGACUCUCUGUUC-3';

Hsp70 siRNA antisense,

5'-ACAGAGAGUCGAUCUCCAGGC-3';

a scramble siRNA sense,

5'-GAAGCGAGAUAUCCCUGACTT-3';

a scramble siRNA antisense, 5'-GUCAGGGAUAUCUCGCUUCTT-3'.

RNA Extraction and Real-Time Polymerase Chain Reaction Total RNAs were extracted from HL-1 cells using an RNeasy Plus mini kit (QIAGEN, Tokyo, Japan). RNA samples were treated with DNase I (Promega, Tokyo, Japan) to eliminate genomic DNA, and cDNA was synthesized by using a PrimeScript ${ }^{\mathrm{TM}}$ RT reagent kit (Takara, Kusatsu, Japan). Real-time polymerase chain reaction (RT-PCR) was conducted with the 7900HT Fast real-time RT-PCR System, and a 384-well plate (Applied Biosystems, Foster City, CA, USA). The universal ProbeLibrary (Roche, Basel, Switzerland) probes no. 1 and no. 64 were used for Kv1.5 and $\beta$-actin respectively. Kv1.5 primers (forward, agg ctc ctc agg atg cag; reverse, gca acc cgg aga tgt tta $\mathrm{tg}$ ) were used to obtain a $63 \mathrm{bp}$ products. Beta-actin primers (forward, cca acc gcg aga aga tga; reverse, cca gag gcg tac agg gat ag) yielded a $97 \mathrm{bp}$ product. Data analysis was conducted with the SDS software version 3.2 (Applied Biosystems).

\section{Uric Acid Uptake Measurement}

The kinetic behavior of uric acid transports was examined by uptake studies using confluent HL-1 cells. They were cultured in 24-well tissue culture plates at a density of $1 \times 10^{5}$ cells/well. After cells were cultured for 2 days, they were washed twice with serum- and chloride-free Hanks' balanced salt solution (HBSS) containing $125 \mathrm{mmol} / \mathrm{L} \mathrm{Na}$ gluconate, $4.8 \mathrm{mmol} / \mathrm{L} \mathrm{K}$ gluconate, $1.2 \mathrm{mmol} / \mathrm{L} \mathrm{KH}_{2} \mathrm{PO}_{4}$, $1.2 \mathrm{mmol} / \mathrm{L} \mathrm{MgSO}_{4}, 1.3 \mathrm{mmol} / \mathrm{L} \mathrm{Ca}$ gluconate, $5.6 \mathrm{mmol} / \mathrm{L}$ glucose and $25 \mathrm{mmol} / \mathrm{L}$ HEPES (pH 7.4), and then preincubated in the same solution in a water bath at $37^{\circ} \mathrm{C}$ for $10 \mathrm{~min}$. The cells were then incubated in the HBSS containing $5 \mu \mathrm{mol} / \mathrm{L}\left[{ }^{14} \mathrm{C}\right]$ urate at $37^{\circ} \mathrm{C}$ for $1-10 \mathrm{~min}$. The uptake was stopped by adding ice-cold HBSS, and the cells were washed twice with the same solution. The cells in each well were lysed with $0.5 \mathrm{~mL}$ of $0.1 \mathrm{~N}$ sodium hydroxide and added to $2.5 \mathrm{~mL}$ of INSTA-GEL PLUS (Perkin Elmer, Yokohama, Japan), and radioactivity was determined using a $\beta$-scintillation counter (LSC-3100; Aloka, Tokyo, Japan). To evaluate the uric acid uptake via URATv1, HL-1 cells were incubated in a solution containing $5 \mu \mathrm{mol} / \mathrm{L}\left[{ }^{14} \mathrm{C}\right]$ urate in the absence or presence of $10 \mu \mathrm{mol} / \mathrm{L}$ benzbromarone at $37^{\circ} \mathrm{C}$ for $1-10 \mathrm{~min}$.

\section{Immunoblotting and Immunoprecipitation (IP)}

The protein was extracted from HL-1 cells and subjected to immunoblotting, as described elsewhere. ${ }^{8}$ Cells were collected in a lysis buffer containing $1 \times \mathrm{PBS}, 1 \%$ nonidet P-40 (w/w), 0.5\% sodium deoxycholate, $0.1 \%$ sodium dodecyl sulphate, $10 \mu \mathrm{g} / \mathrm{mL}$ aprotinin, $10 \mu \mathrm{g} / \mathrm{mL}$ leupeptine, $10 \mu \mathrm{g} / \mathrm{mL}$ pepstatin and $1 \mathrm{mmol} / \mathrm{L}$ phenylmethylsulfonyl fluoride. After repeated pipetting, insoluble materials were removed by centrifugation, and the protein concentration in the supernatant was determined using the Bradford Protein Assay. An aliquot of $10-25 \mu \mathrm{g}$ proteins was subjected to sodium dodecylsulfate poly-acrylamide gel electrophoresis (SDS-PAGE) and electrotransferred to a 


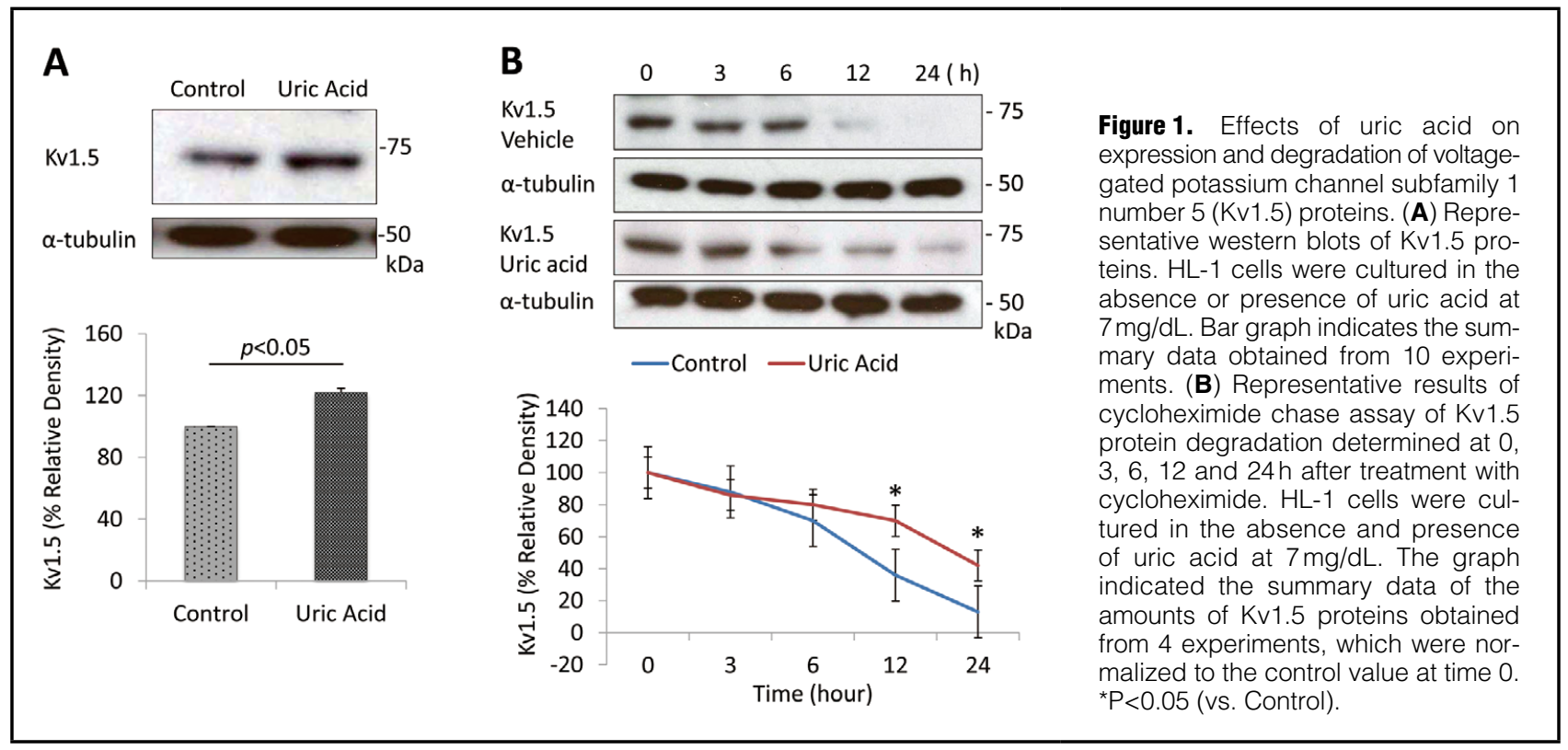

polyvinylidene fluoride (PVDF) membrane. Membranes were probed with primary antibodies against Kv1.5 (1:400; Alomone Labs, Jerusalem, Israel), $\alpha$-tubulin (1:5,000; Abcam, Tokyo, Japan), phosphorylated Akt (p-Akt) (1:2,000; Cell Signaling Technology, Tokyo, Japan), total Akt (1:1,000; Cell Signaling Technology), phosphorylated HSF1 (p-HSF1) (1:1,000; Abcam), total HSF1 (1:1,000; Cell Signaling Technology), and Hsp70 (1:1,000; Stressgen). Secondary antibodies were horseradish-peroxidase-linked anti-rabbit IgG or anti-mouse IgG (1:3,000; GE-Healthcare Limited, UK). The blots were developed using an ECL system (Amersham Biosciences, Tokyo, Japan). Band intensities were quantified using ImageJ $1.50 \mathrm{i}$ software (National Institute of Health, Bethesda, MD, USA). For IP, proteins were incubated in the buffer with protein $G$ agarose (Pharmacia, Uppsala, Sweden) bound with antibodies against $\mathrm{Kv} 1.5$ for $16 \mathrm{~h}$ at $4^{\circ} \mathrm{C}$; following the wash with the buffer, bound proteins were eluted by heating at $37^{\circ} \mathrm{C}$ for $20 \mathrm{~min}$ in SDS-PAGE sample buffer. The bound proteins were analyzed by using SDS-PAGE, followed by immunoblotting using anti-ubiquitin antibody (Medical \& Biological Laboratory Co. Ltd, Nagoya, Japan).

\section{Chase Experiment}

To analyze the stability of Kv1.5 proteins, chase experiments using cycloheximide were performed, as described elsewhere. ${ }^{15}$ HL-1 cells were seeded in 6-well plates in the absence or presence of uric acid. After the addition of cycloheximide $(60 \mu \mathrm{g} / \mathrm{mL})$, cell lysates were prepared at $3-24 \mathrm{~h}$. The lysates were centrifuged at $150,000 \mathrm{rpm}$ for $10 \mathrm{~min}$ at $4^{\circ} \mathrm{C}$, and insoluble materials were discarded. Equal amounts of the protein were subjected to immunoblotting.

\section{Electrophysiological Recordings}

After the treatment with uric acid, Kv1.5 channel currents corresponding to the ultra-rapid delayed-rectifier potassium channel current (IKur) were measured, as described elsewhere. ${ }^{8}$ Outward membrane currents were elicited every $6 \mathrm{~s}$ by 300 -ms test pulses ranging from -60 to $+80 \mathrm{mV}$ (in
$10 \mathrm{mV}$ increments) with a holding potential (HP) of $-60 \mathrm{mV}$. A specific inhibitor of Kv1.5 channel currents, 4-aminopyridine (4-AP), at $100 \mu \mathrm{mol} / \mathrm{L}$ was used to isolate IKur. To eliminate the contamination by another outward current, rapidly activating delayed-rectifier potassium channel current $\left(I_{\mathrm{Kr}}\right)$, and L-type $\mathrm{Ca}^{2+}$ channel current ( $\left.I_{\mathrm{CaL}}\right)$, outward currents were recorded in the presence of both $5 \mu \mathrm{mol} / \mathrm{L} \mathrm{E} 4031$ and $5 \mu \mathrm{mol} / \mathrm{L} \mathrm{Cd}^{2+}$, which almost completely block $I_{\mathrm{Kr}}$ and $I_{\mathrm{CaL}}$ respectively. Thus, the outward currents measured here were 4-AP-sensitive, E4031-insensitive currents corresponding to $I_{K u r}$. The extracellular solution contained (mmol/L) $140 \mathrm{NaCl}, 4 \mathrm{KCl}$, $1.8 \mathrm{CaCl}_{2}, 0.53 \mathrm{MgCl}_{2}, 0.33 \mathrm{NaH}_{2} \mathrm{PO}_{4}, 5.5$ glucose, and 5 HEPES, with $\mathrm{pH}$ adjusted to 7.4 by $\mathrm{NaOH}$. The internal pipette solution contained (mmol/L) $100 \mathrm{~K}$-aspartate, 20 $\mathrm{KCl}, 1 \mathrm{CaCl}_{2}, 5 \mathrm{Mg}$-ATP, 5 EGTA, $5 \mathrm{HEPES}$, and 5 creatine phosphate dipotassium ( $\mathrm{pH} 7.2$ with $\mathrm{KOH})$. Patch pipettes had resistances of 5-10 M $\Omega$ when filled with the pipette solution. Series resistance $\left(R_{s}\right)$ was determined by fitting a single exponential function to the capacitive current decay to estimate its time constant and the membrane capacitance. After the $\mathrm{R}_{\mathrm{s}}$ compensation of $50-60 \%$, the voltage errors arising from $\mathrm{R}_{\mathrm{s}}$ were estimated to be less than $5 \mathrm{mV}$. The membrane potential was not corrected for the liquid junction potential, which was estimated to be $<10 \mathrm{mV}$. Currents were recorded at $37^{\circ} \mathrm{C}$ with an Axopatch200B amplifier (Molecular Devices, San Jose, CA, USA) and directly stored in a personal computer (NEC Mate, Tokyo, Japan) at $10 \mathrm{kHz}$. The capacity-corrected data were digitally filtered at $2 \mathrm{kHz}$, then analyzed using pCLAMP9 software on the computer.

\section{Luciferase Assay}

A reporter gene that encodes firefly luciferase driven by the promoter of Hsp70 was a gift from A. Nakai (Yamaguchi University, Japan). Co-transfection of pRL renilla luciferase control reporter vector (pRL-TK) (Promega, Fitchburg, WI, USA) and pHsp70 promoter firefly luciferase was performed at the ratio of 1:5, using lipofectamine 3000. At indicated time points, cells were trypsinized to be detached 
A

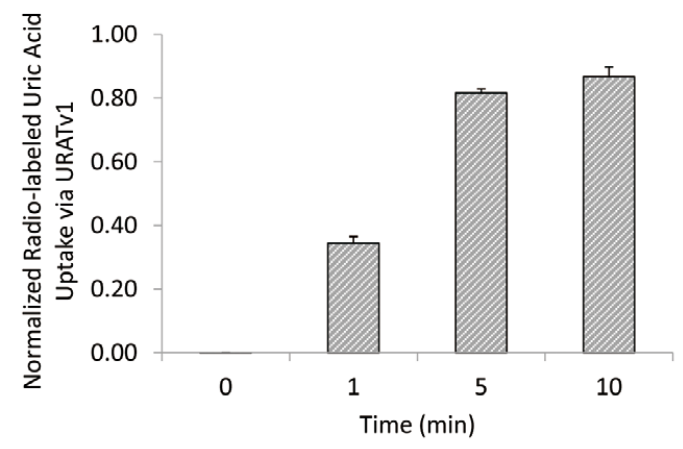

B

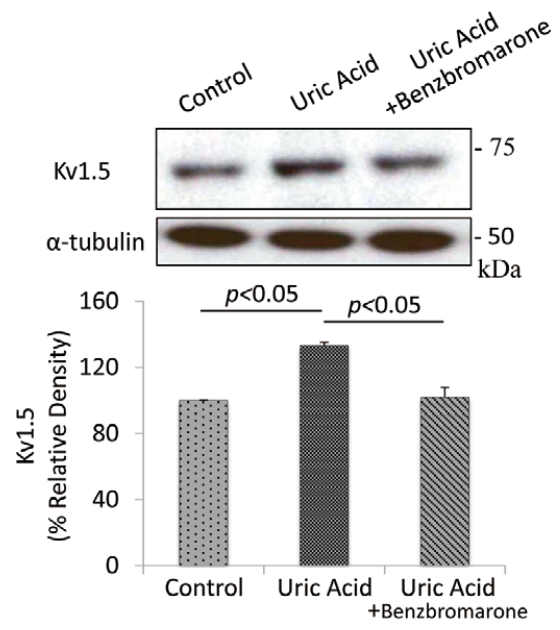

Figure 2. Intracellular uric acid incorporated through voltage-driven uric acid influx transporter (URATV1) stabilized voltage-gated potassium channel subfamily 1 number 5 (Kv1.5) proteins. (A) Intracellular accumulation of uric acid labeled by ${ }^{14} \mathrm{C}$. $\mathrm{HL}-1 \mathrm{cells}$ were cultured in the hyperuricemic condition of uric acid at $7 \mathrm{mg} / \mathrm{dL}$. Intracellularly accumulated uric acid through URATV1 was defined as the difference between the amounts of ${ }^{14} \mathrm{C}$-uric acid in the absence and presence of $10 \mu \mathrm{mol} / \mathrm{L}$ benzbromarone. Summary data of the intracellularly accumulated uric acid levels at $0-10 \mathrm{~min}$ normalized to that in a steady state are shown ( $\mathrm{n}=9$ ). (B) Benzbromarone $(10 \mu \mathrm{mol} / \mathrm{L})$ abolished the uric acid-induced increase of Kv1.5 proteins. The bar graph shows the summary data obtained from 3 experiments.

A

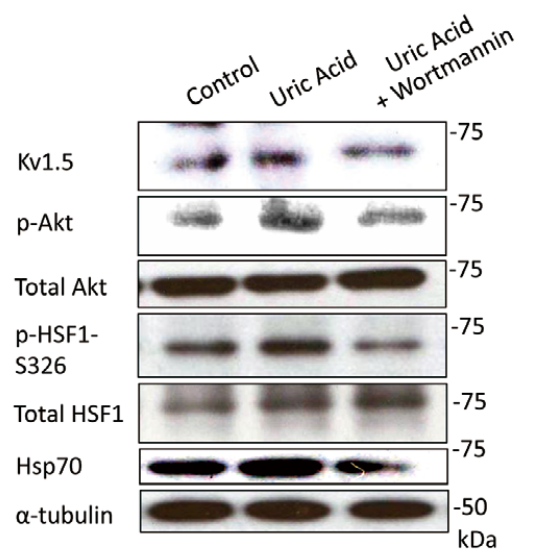

B

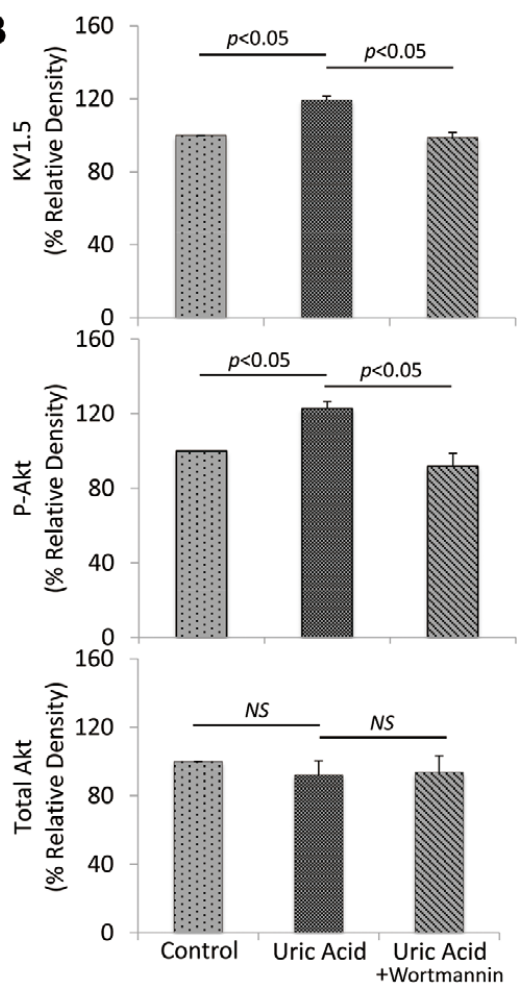

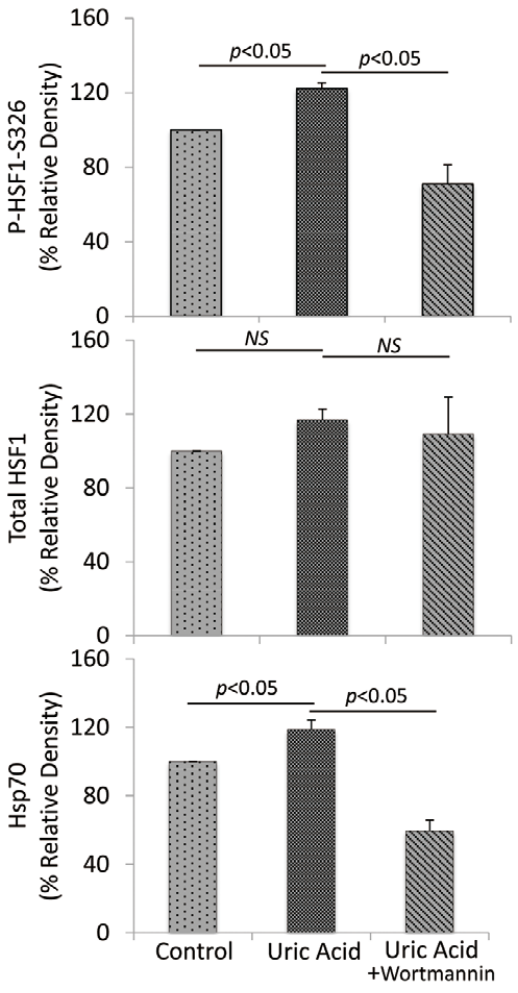

Figure 3. Effects of uric acid on phosphorylation of Akt and heat shock factor 1 (HSF1) and expression of heat shock protein 70 (Hsp70) in the absence and presence of an phsphoinositide-3-kinase (PI3K) inhibitor, wortmannin. Shown are representative western blots $(\mathbf{A})$ and summary data obtained from 4 experiments (B) indicating effects of uric acid and wortmannin on phosphorylation of Akt and HSF1, and protein levels of voltage-gated potassium channel subfamily 1 number 5 (Kv1.5) and Hsp70. Cells were treated with uric acid at $7 \mathrm{mg} / \mathrm{dL}$ in the absence or presence of $1 \mu \mathrm{mol} / \mathrm{L}$ wortmannin. 

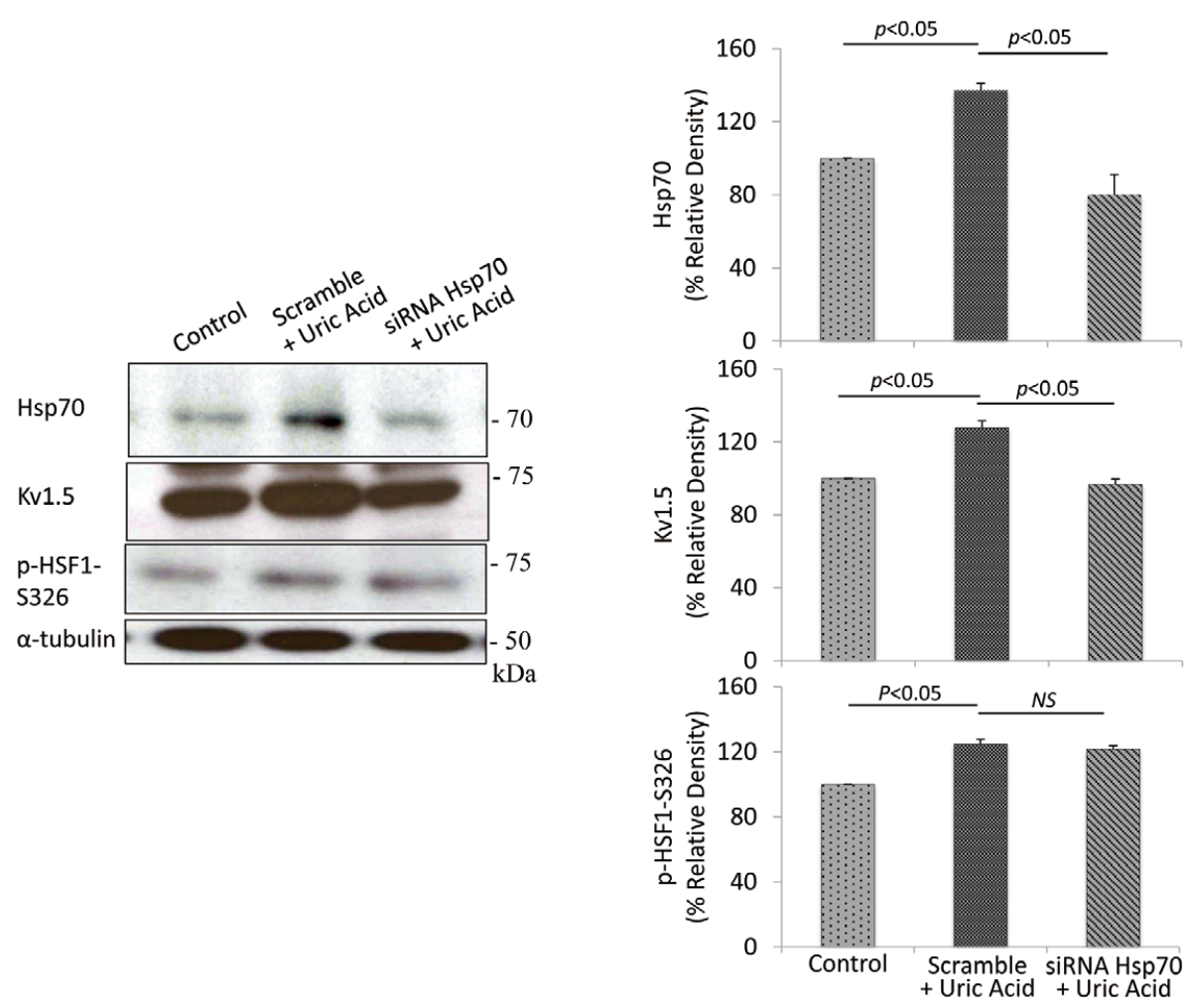

Figure 4. Effects of knockdown of heat shock protein $70(\mathrm{Hsp} 70)$ on the uric acid-induced enhancement of phosphorylation of heat shock factor 1 (HSF1) and voltage-gated potassium channel subfamily 1 number 5 (Kv1.5) expression. Protein levels of Hsp70, Kv1.5 and phosphorylated HSF1 in HL-1 cells treated with uric acid (7 mg/dL) and siRNA against Hsp70 or a scramble siRNA. Shown are representative western blots (Left) and the summary data obtained from 4 experiments (Right).

from the culture plate. Luciferase activities were measured using Dual Luciferase Reporter Assay System (Promega), and analyzed a with Tecan i-control ${ }^{\mathrm{TM}} 1.6$ microplate reader (Tecan Trading AG, Switzerland). Hsp70-firefly luciferase activity was normalized to renilla luciferase activity.

\section{Data Analysis}

The data were presented as mean $\pm \mathrm{SD}$, and the graphs were built using Excel 2011 for Mac. Data were checked for its distribution before further analysis. Analysis of variance (ANOVA) followed by the Turkey-Kramer, Steel-Dwass, and Scheffe post-hoc tests was used to assess the difference between multiple groups.

A P value of $<0.05$ was considered as significant. All of the statistical analyses were performed using IBM SPSS Statistic Version 23.

\section{Results}

\section{Uric Acid Stabilized Kv1.5 Proteins via Post-Translational Modifications in HL-1 Cells}

We first examined the effects of uric acid $(4-7 \mathrm{mg} / \mathrm{dL}$, for $24 \mathrm{~h})$ on Kv1.5 protein levels in HL-1 cells. Figure 1A shows the representative western blot illustrating an increase of Kv1.5 proteins induced by uric acid at $7 \mathrm{mg} / \mathrm{dL}$. Summary data obtained from 10 experiments indicated that uric acid significantly increased the protein level of Kv1.5 in HL-1 cells. As shown in Supplementary Figure 1, uric acid enhanced Kv1.5 expression in a concentrationdependent manner: Kv1.5 proteins were increased slightly but not significantly by uric acid at $4 \mathrm{mg} / \mathrm{dL}$, but were increased significantly at $7 \mathrm{mg} / \mathrm{dL}$. We next examined whether uric acid increased the mRNA level of Kv1.5 by qRT-PCR (Supplementary Figure 2). Uric acid at $7 \mathrm{mg} / \mathrm{dL}$ did not change the mRNA level of Kv1.5, indicating that uric acid may influence the stability of Kv1.5 proteins. To evaluate the effects of uric acid on the stability of Kv1.5 proteins, we further conducted chase experiments (Figure 1B). Uric acid suppressed degradation of Kv1.5 proteins, mimicking the effect of the proteasome inhibitor, MG132, on degradation of Kv1.5 proteins. ${ }^{17}$ Summary data obtained from 4 experiments indicated that uric acid significantly slowed degradation of Kv1.5 proteins after the addition of cycloheximide. Uric acid could also decrease ubiquitinated Kv1.5 proteins (Supplementary Figure 3). These findings suggest that uric acid inhibits ubiquitination and proteasomal degradation of Kv1.5 proteins.

\section{Kv1.5 Proteins Were Stabilized by Uric Acid Intracellularly Accumulated via URATv1}

We hypothesized that the uric acid-induced stabilization of $\mathrm{Kv} 1.5$ proteins is attributable to an intracellular accumulation of uric acid. It has been reported that HL-1 cells express the uric acid influx transporter, URATv1, and two efflux transporters, ABCG2 and MRP4. ${ }^{8}$ We measured uric acid uptake through URATv1 into the HL-1 cell using 
A

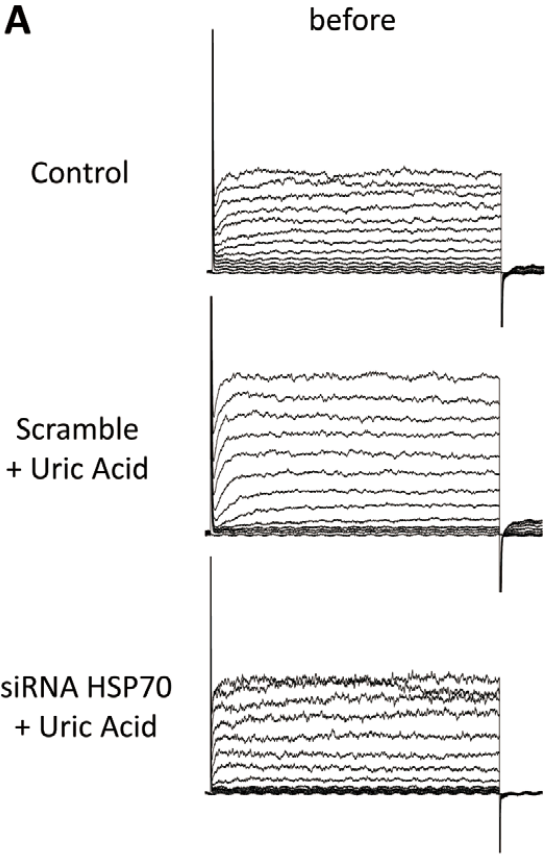

4-AP treatment

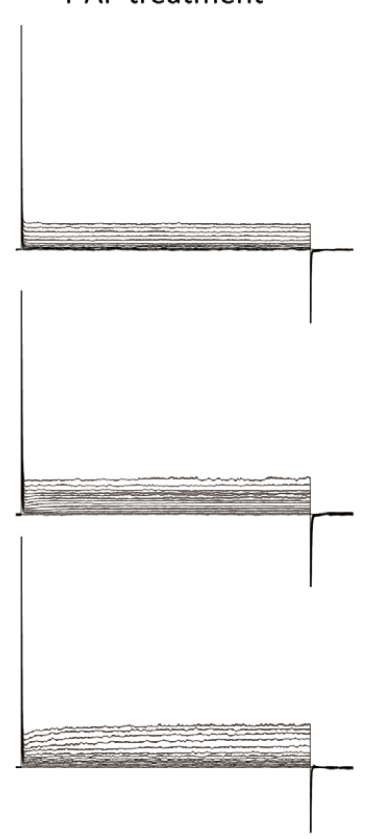

4-AP sensitive currents

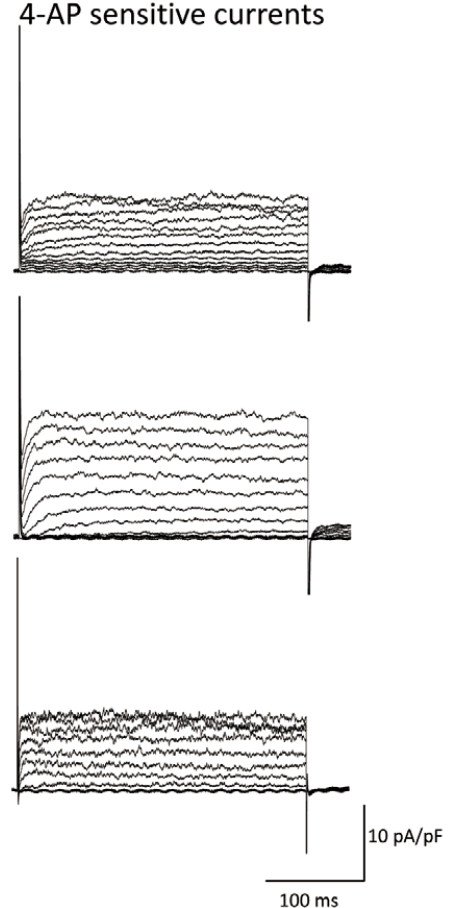

B

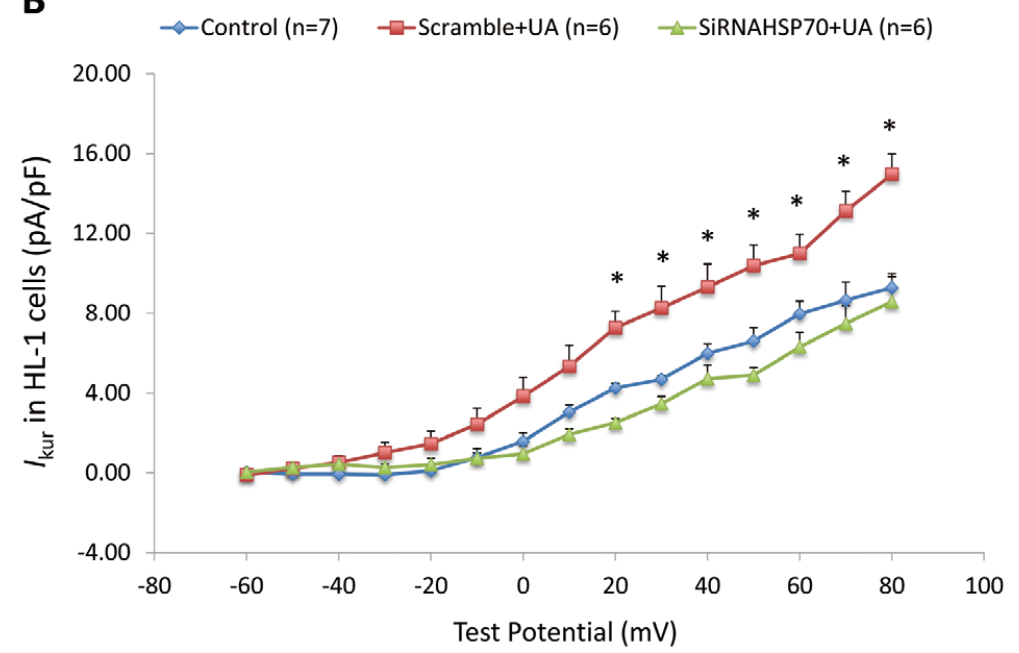

Figure 5. Effects of uric acid and knockdown of heat shock protein 70 (Hsp70) on the voltage-gated potassium channel subfamily 1 number 5 (Kv1.5) channel current, Kur. (A) Patch clamp records of outward membrane currents elicited before (Left) and during (Middle) administration of 4-AP $(100 \mu \mathrm{mol} / \mathrm{L})$ in $\mathrm{HL}-1$ cells transfected with either scramble siRNA or siRNA against Hsp70 and treated with or without uric acid at $7 \mathrm{mg} / \mathrm{dL}$. 4-AP-sensitive currents were determined by subtracting the current in the presence of 4-AP from that in the absence of the agent (Right). (B) Summary data on the current-voltage relationships of the 4-AP sensitive currents in the absence and presence of uric acid (UA) obtained from 6 to 7 experiments. ${ }^{*} \mathrm{P}<0.05$ (vs. Control).

${ }^{14} \mathrm{C}$-uric acid. Figure $2 \mathrm{~A}$ shows the time-dependent ${ }^{14} \mathrm{C}$-uric acid uptake via URATv1, determined as the difference between the amounts of incorporated ${ }^{14} \mathrm{C}$-uric acid in the absence and presence of the URATv1 inhibitor, benzbromarone, at $10 \mu \mathrm{mol} / \mathrm{L}$, which was normalized to a steadystate value. HL-1 cells incorporated ${ }^{14} \mathrm{C}$-uric acid in a time-dependent manner, indicating that uric acid was incorporated into the cells via URATv1. To verify the role of URATV1, we examined effects of benzbromarone on the uric acid-induced increase of Kv1.5 proteins. Figure 2B shows the representative western blot of Kv1.5 proteins in HL-1 cells after a 24-h treatment with uric acid at $7 \mathrm{mg} / \mathrm{dL}$ in the presence and absence of benzbromarone $(10 \mu \mathrm{mol} / \mathrm{L})$. Uric acid could not enhance Kv1.5 expression in the presence of benzbromarone. The summarized data confirmed that benzbromarone abolished the effect of uric acid on Kv1.5 expression, indicating the pivotal role of URATv1 in the uric acid-induced stabilization of Kv1.5 proteins. 


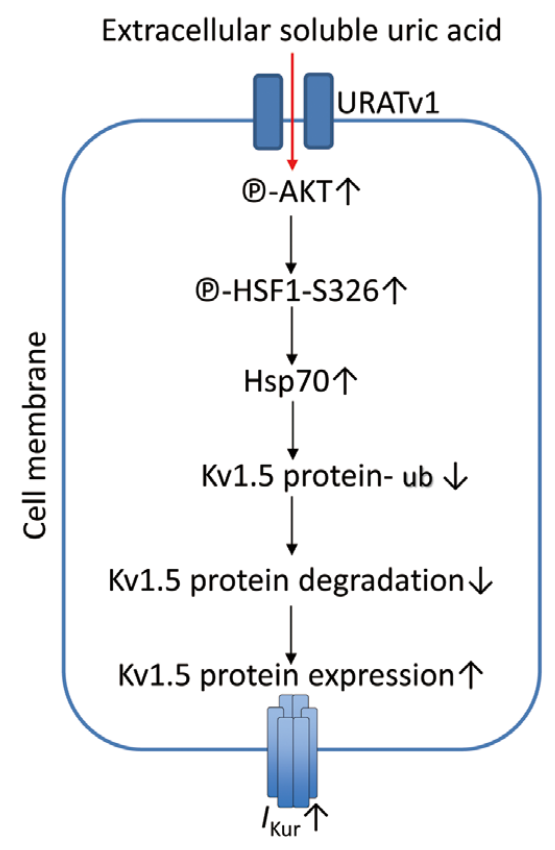

Figure 6. A schematic diagram of possible mechanisms for the uric acid-induced stabilization of voltage-gated potassium channel subfamily 1 number 5 (Kv1.5) proteins and enhancement of /kur. Ubiquitinated Kv1.5 protein is denoted as "Kv1.5 protein-ub".

\section{Roles of p-Akt, p-HSF1 and Hsp70 in Uric Acid-Induced Stabilization of Kv1.5 Proteins}

We reported that the uric acid-induced enhancement of Kv1.5 expression could be attributable to ROS-dependent phosphorylation of the extracellular signal-regulated kinase (ERK) ${ }^{8}$ As ROS has also been reported to activate the PI3K/Akt/mTOR pathway, ${ }^{11}$ we examined whether this pathway is involved in the uric acid-induced increase of Kv1.5 proteins. We first tested effects of uric acid on the protein levels of p-Akt and Kv1.5 in the absence and presence of wortmannin $(1 \mu \mathrm{mol} / \mathrm{L})$, a specific inhibitor of PI3K (Figure 3A). Uric acid at $7 \mathrm{mg} / \mathrm{dL}$ increased p-Akt without changes in the level of total Akt. This facilitated Akt phosphorylation was accompanied by an increase of Kv1.5 proteins, as summarized in Figure 3B (Left). Wortmannin abolished the uric acid-induced enhancement of Akt phosphorylation and Kv1.5 expression (Figure 3A and $\mathbf{B}$, Left). These findings suggest that phosphorylation of Akt is required for uric acid to increase the protein level of Kv1.5. It has been reported that HSF1 activation increases the protein level of Kv1.5 in HL-1 cells via enhancing expression of Hsp70.14 Thus, we examined whether uric acid could increase Hsp70 expression and phosphorylated HSF1-S326 (p-HSF1-S326), which is associated with transcriptional activation (Figure 3A and B, Right). ${ }^{18,19}$ Uric acid increased p-HSF1-S326 without significant changes in the total HSF1. This enhanced HSF1 phosphorylation was accompanied by an increase of Hsp70. These effects of uric acid were abolished by the PI3K inhibitor, wortmannin. Thus, uric acid facilitated PI3K-dependent phosphorylation of Akt and HSF1 and Hsp70 expression, thereby stabilizing Kv1.5 proteins.

We next examined whether the increase of Hsp70 is responsible for the increase of Kv1.5 proteins. HL-1 cells were transfected with a siRNA against $\mathrm{Hsp} 70$ or a scramble siRNA. Uric acid increased the levels of Hsp70 and Kv1.5 proteins only in cells transfected with the scramble siRNA (Figure 4). The siRNA against Hsp70 abolished the effects of uric acid on Kv1.5 protein expression, but did not affect its effect on p-HSF1-S326. The promoter assay confirmed that uric acid increased transcription of Hsp70 (Supplementary Figure 4). These findings indicate that uric acid facilitates phosphorylation of HSF1 and thereby increases Hsp70 to stabilize Kv1.5 proteins.

\section{Uric Acid Increased the Kv1.5 Channel Current, Ikur}

Figure 5A shows original traces of 4-AP-sensitive $I_{K u r}$ in HL-1 cells transfected with the siRNA against Hsp70 or the scrambled siRNA and treated with or without uric acid. Depolarizing test pulses from a HP of $-60 \mathrm{mV}$ elicited time-dependent outward currents, which were almost completely blocked by $4-\mathrm{AP}$ at $100 \mu \mathrm{mol} / \mathrm{L}$. Treatment with uric acid increased the amplitude of $I_{\text {Kur }}$ in the HL-1 cells transfected with the scrambled siRNA, but not in those transfected with the siRNA against Hsp70. Uric acid did not influence the capacitive currents $(35.4 \pm 1.8 \mathrm{pF}$ in control; $37.3 \pm 1.6 \mathrm{pF}$ with uric acid and the scramble siRNA; $35.5 \pm 0.5 \mathrm{pF}$ with uric acid and the siRNA against Hsp70). Summary data of the voltage-dependent activation of $I_{\text {Kur }}$ in HL-1 cells indicated that uric acid significantly augmented IKur in a potential range from +20 to $+80 \mathrm{mV}$ without affecting the threshold potential, but knockdown of Hsp70 abolished the action of uric acid on IKur (Figure 5B).

\section{Discussion}

In the present study, we found that: (1) uric acid increased the protein level of Kv1.5 in HL-1 cells via inhibiting ubiquitination and proteasomal degradation of the protein without changes in the mRNA level; (2) inhibition of URATv1 prevented the uric acid-induced enhancement of Kv1.5 expression; (3) uric acid facilitated phosphorylation of Akt and HSF1, and expression of Hsp70 to increase Kv1.5 proteins; and (4) uric acid increased IKur, which was abolished by knockdown of Hsp70.

Biological actions of uric acid have been described in mammalian cells including human cells. Although uric acid is recognized as an antioxidant at physiological concentrations, ${ }^{20}$ it may act in an opposite way under hyperuricemic conditions. ${ }^{21}$ Many studies reported a relationship between hyperuricemia and cardiovascular morbidities. ${ }^{22-24}$ Recently, we reported that uric acid could be an independent risk factor for AF in healthy subjects. ${ }^{5}$ As for a mechanism underlying the association of hyperuricemia and $\mathrm{AF}$, we recently reported that intracellular uric acid could enhance the expression of Kv1.5 and its channel current in HL-1 atrial myocytes, which was abolished by the URATV1 inhibitor, benzbromarone. ${ }^{8}$

$\mathrm{Kv} 1.5$ channel expression is regulated both transcriptionally and translationally. The expression of Kv1.5 channel proteins on the plasma membrane depends on the balance between protein biosynthesis and degradation. ${ }^{25,26}$ Delayed degradation through the ubiquitin-proteasome system may be involved in the uric acid-induced increase of Kv1.5 expression as described in the present study. We did not observe any significant effect of uric acid on mRNA of $\mathrm{Kv1}$.5, suggesting post-translational modifications of Kv1.5 proteins facilitated by uric acid. 
Several reports indicated that hyperuricemia induced oxidative stress to stimulate the downstream PI3K/Akt/ mTOR signaling pathway. Our previous study implicated that uric acid-induced ROS production via NADPH oxidase activation could stabilize the Kv1.5 protein. ${ }^{8}$ However, it has been reported that degradation of Kv1.5 proteins is accelerated by prolonged oxidative stress. ${ }^{27}$ This inconsistency might be explained by differences in oxidative stress, which activates the downstream signaling pathway. There are several lines of evidence for the role of uric acid as a regulator of cellular signaling pathways through ROS production. In the present study, we demonstrated that uric acid facilitated phosphorylation of Akt. p-Akt activates the PI3K/Akt/mTOR pathway and plays important roles in cell proliferation and survival. Activation of this pathway also correlates with the ROS level. Several reports showed that ROS could activate the PI3K/Akt/mTOR pathway and that this pathway played a pivotal role for ROS generation. ${ }^{10,11,28}$ In the current study, uric acid increased p-Akt and Kv1.5 proteins, these effects being suppressed by the PI3K inhibitor wortmannin. This finding indicates that uric acid enhances PI3K-dependent phosphorylation of Akt to stabilize Kv1.5 proteins.

The most important finding is that uric acid-induced facilitation of Akt phosphorylation could link to enhanced expression and phosphorylation of the heat shock protein family to stabilize Kv1.5 proteins; uric acid enhanced Kv1.5 protein expression through the $\mathrm{p}$-Akt-induced increment of p-HSF1 and increased expression of Hsp70. We have reported that a proteasome inhibitor prolongs Kv1.5 protein's half-life and increases both Kv1.5 protein expression and channel currents. ${ }^{25,26}$ Ubiquitination of Kv1.5 proteins was increased by overexpression of carboxylterminus heat shock cognate 70 -interacting protein (CHIP), an E3 ubiquitin ligase, and co-expression of CHIP and heat shock cognate 70 (Hsc70) enhanced Kv1.5 protein degradation. ${ }^{25}$ HSF1 is activated by oxidative stress; ${ }^{6}$ activation of HSF1 by oxidative stress induces the enhanced expression of heat shock proteins. ${ }^{29,30} \mathrm{We}$ previously reported that activation of HSF1 stabilized Kv1.5 proteins via an increased expression of the anchoring protein, SAP97.13 Whether uric acid increases SAP97 through phosphorylation of HSF1 should be examined in a future study.

As a possible mechanism for the uric acid-induced stabilization of Kv1.5 proteins and enhancement of $I_{\mathrm{Kur}}$, we provide a scheme of interactions of every key molecule, as shown in Figure 6. The intracellularly accumulated uric acid stabilizes Kv1.5 proteins and enhances Kv1.5 channel currents via promoting ROS-dependent phosphorylation of Akt and HSF1, and Hsp70 expression.

Clinical implications of the uric acid-induced stabilization of Kv1.5 proteins may be obvious. The present study suggests that hyperuricemia, causing oxidative stress on cardiomyocytes, leads to the intracellular accumulation of uric acid through activation of UATs such as URATv1, which causes the enhancement of IKur via the Akt-HSF1Hsp70 pathway and resultant shortening of the atrial action potential and refractory period. As the uric acid-induced atrial action potential shortening could facilitate the development of re-entry circuits in the atrium, hyperuricemia may cause atrial arrhythmias including AF. Recently, we reported that hyperuricemia is an independent competing risk factor for $\mathrm{AF},{ }^{\mathbf{5}}$ which may be in favor of the present result that uric acid could facilitate the occurrence of re-entrant arrhythmias in the atrium. Although further prospective intervention studies are needed to prove whether lowering serum uric acid levels is effective for preventing AF, inhibition of the Akt-HSF1-Hsp70 pathway may be the novel therapeutic approach against $\mathrm{AF}$ in hyperuricemic patients.

\section{Conclusions}

We investigated the effects of uric acid on mRNA and protein levels of Kv1.5, as well as those of Akt, HSF1 and Hsp70, in HL-1 cardiomyocytes. The uptake of uric acid and $\mathrm{Kv1} 1.5$-mediated $\mathrm{K}^{+}$channel currents was also measured. Intracellularly accumulated uric acid significantly enhanced the expression of Kv1.5 proteins and channel currents via slowed degradation of Kv1.5 proteins, which is attributable to enhanced phosphorylation of Akt and HSF1 leading to increased expressions of Hsp70.

\section{Disclosures}

The authors have no conflicts of interest to disclose.

\section{Funding}

This work was supported by a Grant-in-Aid for Scientific Research (C) from the Japan Society for the Promotion of Science (No. 18K08074 to P. Li) and Gout Research Foundation 2017 (to I.H.).

\section{References}

1. Maiuolo J, Oppedisano F, Gratteri S, Muscoli C, Mollace V. Regulation of uric acid metabolism and excretion. Int J Cardiol 2016; 213: 8-14.

2. Fang J, Alderman MH. Serum uric acid and cardiovascular mortality the NHANES I epidemiologic follow-up study, 19711992: National Health and Nutrition Examination Survey. JAMA 2000; 283: 2404-2410.

3. Feig DI, Kang DH, Johnson RJ. Uric acid and cardiovascular risk. N Engl J Med 2008; 359: 1811-1821.

4. Tamariz L, Agarwal S, Soliman EZ, Chamberlain AM, Prineas $\mathrm{R}$, Folsom AR, et al. Association of serum uric acid with incident atrial fibrillation (from the Atherosclerosis Risk in Communities [ARIC] Study). Am J Cardiol 2011; 108: 1272-1276.

5. Kuwabara M, Niwa K, Nishihara S, Nishi Y, Takahashi O, Kario K, et al. Hyperuricemia is an independent competing risk factor for atrial fibrillation. Int J Cardiol 2017; 231: 137-142.

6. Yu MA, Sánchez-Lozada LG, Johnson RJ, Kang DH. Oxidative stress with an activation of the renin-angiotensin system in human vascular endothelial cells as a novel mechanism of uric acid-induced endothelial dysfunction. J Hypertens 2010; 28: $1234-1242$.

7. Korantzopoulos P, Kolettis TM, Galaris D, Goudevenos JA. The role of oxidative stress in the pathogenesis and perpetuation of atrial fibrillation. Int J Cardiol 2007; 115: 135-143.

8. Maharani N, Ting YK, Cheng J, Hasegawa A, Kurata Y, Li P, et al. Molecular mechanisms underlying urate-induced enhancement of Kv1.5 channel expression in HL-1 atrial myocytes. Circ J 2015; 79: 2659-2668.

9. Wright AF, Rudan I, Hastie ND, Campbell H. A "complexity" of urate transporters. Kidney Int 2010; 78: 446-452.

10. Ray PD, Huang BW, Tsuji Y. Reactive oxygen species (ROS) homeostasis and redox regulation in cellular signaling. Cell Signal 2012; 24: 981-990.

11. Le Belle JE, Orozco NM, Paucar AA, Saxe JP, Mottahedeh J, Pyle AD, et al. Proliferative neural stem cell have high endogenous ROS levels that regulate self-renewal and neurogenesis in PI3K/ Akt-dependent manner. Cell Stem Cell 2011; 8: 59-71.

12. Vihervaara A, Sistonen L. HSF1 at a glance. J Cell Sci 2014; 127: $261-266$.

13. Bironaite D, Brunk U, Venalis A. Protective induction of Hsp70 in heat-stressed primary myoblasts: Involvement of MAPKs. $J$ Cell Biochem 2013; 114: 2024-2031.

14. Ting YK, Morikawa K, Kurata Y, Li P, Bahrudin U, Mizuta E, et al. Transcriptional activation of the anchoring protein SAP97 by heat shock factor (HSF)-1 stabilizes $\mathrm{K}$ (v) 1.5 channels in 
HL-1 cells. Br J Pharmacol 2011; 162: 1832-1842.

15. Hirota Y, Kurata Y, Kato M, Notsu T, Koshida S, Inoue T, et al. Functional stabilization of Kv1.5 protein by Hsp70 in mammalian cell lines. Biochem Biophys Res Commun 2008; 372: 469-474.

16. Yamanaka H; Japanese Society of Gout and Nucleic Acid Metabolism. Japanese guideline for the management of hyperuricemia and gout: Second edition. Nucleosides Nucleotides Nucleic Acids 2011; 30: 1018-1029.

17. Suzuki S, Kurata Y, Li P, Notsu T, Hasegawa A, Ikeda N, et al. Stabilization of Kv1.5 channel protein by bepridil through its action as a chemical chaperone. Eur J Pharmacol 2012; 696: $28-34$.

18. Guettouche T, Boellmann F, Lane WS, Voellmy R. Analysis of phosphorylation of human heat shock factor 1 in cells experiencing a stress. BMC Biochem 2005; 6: 4.

19. Tang Z, Dai S, He Y, Doty RA, Shultz LD, Sampson SB, et al. MEK guards proteome stability and inhibits tumor-suppressive amyloidogenesis via HSF1. Cell 2015; 160: 729-744.

20. Ames BN, Cathcart R, Schwiers E, Hochsteint P. Uric acid provides an antioxidant defense in humans against oxidant- and radical-caused aging and cancer: A hypothesis. Proc Natl Acad Sci USA 1981; 78: 6858-6862.

21. Sautin YY, Nakagawa T, Zharikov S, Johnson RJ. Adverse effects of the classic antioxidant uric acid in adipocytes: NADPH oxidase-mediated oxidative/nitrosative stress. Am J Physiol Cell Physiol 2007; 293: C584-C596.

22. Jia L, Xing J, Ding Y, Shen Y, Shi X, Ren W, et al. Hyperuricemia causes pancreatic $\beta$-cell death and dysfunction through NF- $\kappa \mathrm{B}$ signaling pathway. PLoS One 2013; 8: e78284.

23. Schwartz IF, Grupper A, Chernichovski T, Grupper A, Hillel O, Engel A, et al. Hyperuricemia attenuates aortic nitric oxide generation, through inhibition of arginine transport, in rats. $J$ Vasc Res 2011; 48: 252-260.

24. Mazzali M, Kanellis J, Han L, Feng L, Xia YY, Chen Q, et al Hyperuricemia induces a primary renal arteriolopathy in rats by a blood pressure-independent mechanism. Am J Physiol Renal Physiol 2002; 282: F991-F997.

25. Li P, Kurata Y, Maharani N, Mahati E, Higaki K, Hasegawa A, et al. E3 ligase CHIP and $\mathrm{Hsc} 70$ regulate Kv1.5 protein expression and function in mammalian cells. $J$ Mol Cell Cardiol 2015; 86: $138-146$.

26. Kato M, Ogura K, Miake J, Sasaki N, Taniguchi S, Igawa O, et al. Evidence for proteasomal degradation of Kv1.5 channel protein. Biochem Biophys Res Commun 2005; 337: 343-348.

27. Svoboda LK, Reddie KG, Zhang L, Vesely ED, Williams ES, Schumacher SM, et al. Redox-sensitive sulfenic acid modification regulates surface expression of the cardiovascular voltage-gated potassium channel Kv1.5. Circ Res 2012; 111: 842-853.

28. Nieborowska-Skorska M, Flis S, Skorski T. AKT-induced reactive oxygen species generate imatinib-resistant clones emerging from chronic myeloid leukemia progenitor cells. Leukemia 2014; 28: $2416-2418$.

29. Ahn S, Thiele D. Redox regulation of mammalian heat shock factor 1 is essential for Hsp gene activation and protection from stress. Genes Dev 2003; 17: 516-528.

30. Niforou K, Cheimonidou C, Trougakos IP. Molecular chaperones and proteostasis regulation during redox imbalance. Redox Biol 2014; 2: 323-332.

\section{Supplementary Files}

Please find supplementary file(s);

http://dx.doi.org/10.1253/circj.CJ-18-1088 